\title{
Height and surfacing as risk factors for injury in falls from playground equipment: a case-control study
}

\author{
David J Chalmers, Stephen W Marshall, John D Langley, M Jean Evans, \\ Cheryl R Brunton, Anne-Maree Kelly, Alison F Pickering
}

\begin{abstract}
Objectives-Despite the widespread promotion of safety standards no epidemiological studies have adequately evaluated their effectiveness in preventing injury in falls from playground equipment. This study evaluated the effectiveness of the height and surfacing requirements of the New Zealand standard for playgrounds and playground equipment.
\end{abstract}

Setting-Early childhood education centres and schools in two major cities in the South Island of New Zealand.

Methods-Data were collected on 300 children aged 14 years or less who had fallen from playground equipment. Of these, 110 (cases) had sustained injury and received medical attention, while 190 (controls) had not sustained injury requiring medical attention.

Results-Logistic regression models fitted to the data indicated that the risk of injury being sustained in a fall was increased if the equipment failed to comply with the maximum fall height (odds ratio $(O R)=3.0 ; 95 \%$ confidence interval $(C I)$ $0 \cdot 7$ to $13 \cdot 1)$, surfacing $(O R=2 \cdot 3 ; 95 \% C I$ 1.0 to $5 \cdot 0)$, or safe fall height $(O R=2 \cdot 1$; $95 \%$ CI $1 \cdot 1$ to $4 \cdot 0$ ) requirements. Falls from heights in excess of 1.5 metres increased the risk of injury $4 \cdot 1$ times that of falls from 1.5 metres or less and it was estimated that a $45 \%$ reduction in children attending emergency departments could be achieved if the maximum fall height was lowered to $1 \cdot 5$ metres.

Conclusions-Although the height and surfacing requirements of the New Zealand standard are effective in preventing injury in falls from playground equipment, consideration should be given to lowering the maximum permissible fall height to 1.5 metres.

(Injury Prevention 1996; 2: 98-104)

Keywords: falls, play.

Each year in New Zealand approximately 7400 children aged less than 15 years attend emergency departments for the treatment of injuries sustained while using playground equipment, over 1100 are hospitalised, and one dies, giving annual incidence rates per 100000 children of 930 for emergency department attendances, 137 for hospitalisations, and a mortality rate of $0 \cdot 15 .^{1-3}$ These rates do not compare favourably with those for northern hemisphere countries, but are similar to those for Australia. ${ }^{4-6}$ Fifty eight per cent of the emergency department attendances, $92 \%$ of the hospitalisations, and $46 \%$ of the fatalities result from falls. ${ }^{1}$ To reduce these injuries, a safety standard for playgrounds and playground equipment was introduced in 1986 (NZS 5828). ${ }^{7}$ This is similar in many respects to those of other countries. ${ }^{8-11}$ The regulation of equipment height and under surfacing is considered a priority. The specific requirements relating to these factors are described in the Appendix.

There has been widespread promotion of the standard but given that its implementation is voluntary, compliance with the above requirements is by no means universal. A survey of 1135 items of equipment in school and public playgrounds in Dunedin found that $17 \%$ had fall heights exceeding 2.5 metres, $55 \%$ did not have impact absorbing surfaces, and only $4 \%$ complied with the safe fall height requirement. ${ }^{12}$

Four studies have attempted to measure the injury risks associated with height of equipment or type of undersurface, ${ }^{13-16}$ but all four had methodological problems varying from not controlling for exposure ${ }^{131416}$ or height of fall, ${ }^{13-15}$ as well as other confounders. These studies reported evidence of increased risk with increased equipment height but were equivocal as to the benefits of impact absorbing surfaces, such as bark chips, in comparison to nonimpact absorbing surfaces, such as concrete. Because no epidemiological studies have adequately evaluated the effectiveness of impact absorbing surfaces in reducing the incidence and severity of injuries, vigorous debate has occurred, ${ }^{17-21}$ with some researchers arguing that until the evidence is available, no money should be spent on installing expensive surfacing materials. ${ }^{22}$ They argue, further, that whereas the sufaces being widely promoted are 'designed solely to reduce the risk of one particular type of injury, namely, life-

A-M Kelly 
threatening brain injury.... There is no evidence available of their effectiveness as a risk reduction measure for other injuries'. ${ }^{22}$ In fact, there is no 'real world' evidence available of their effectiveness as a risk reduction measure for brain injury either.

The purpose of the present study was to examine height and surfacing as risk factors for injury in falls from playground equipment, and in so doing assess the effectiveness of the requirements of the New Zealand standard in reducing the risk of such injury. The following hypotheses were tested:

(1) Children injured in fall from playground equipment will be more likely than children with minor injuries (or no injuries) to have fallen from equipment non-compliant with the requirements of NZS 5828 regarding: (a) maximum fall height; (b) surfacing; and (c) safe fall heights for specific surfacing materials.

(2) Children injured in falls from playground equipment will be more likely to have fallen from greater heights than children with minor injuries (or no injuries).

\section{Methods}

This study was undertaken in Dunedin and Christchurch, the two most populous cities in the South Island of New Zealand, with approximately 21000 and 60000 children aged 14 years or less, respectively. It was restricted to early childhood education centres (preschool facilities for children aged less than 5 years) and schools (for children aged 5 to 14 years).

Cases were children aged 14 years or less who had sustained injuries in falls from playground equipment at an early childhood education centre or school, and had received medical attention. Staff at the emergency departments of the Dunedin and Christchurch public hospitals recorded the names of all children presenting for treatment who met the above criteria. A written invitation to participate, information sheet, and consent form, were issued to the parent(s) or other care giver(s). The records at Dunedin Hospital were checked weekly throughout the study period (September 1989 to February 1991), while those at Christchurch Hospital were checked each weekday (November 1991 to May 1992). A follow up telephone call was made within one week to arrange an interview.

Controls were children aged 14 years or less who had fallen from playground equipment and had struck the ground surface but had not sustained an injury for which medical attention was sought. Recruitment was through early childhood education centres and schools in the area served by Christchurch Hospital. Incidents were recorded by staff who were contacted twice weekly by telephone. Typically, the incident would have come to the attention of staff because the child had required first aid or, simply reassurance. Participation was invited using the same procedures as for cases.

On the basis of the age distribution of cases ascertained in Dunedin it was decided to seek $86 \%$ of controls from schools and the remain- ing $14 \%$ from early childhood education centres. To maximise the limited time and resources available, only schools with rolls of 200 or more pupils were sampled. Early childhood education centres were similarly restricted to only the larger centres. A random sample of 22 schools and 22 centres from those located in the catchment area for Christchurch Hospital was required to achieve targets of 160 and 25 controls, respectively. Schools were recruited through a direct approach to principals, while early childhood education centres were recruited with the assistance of the relevant parent organisations. In only one instance was a school principal not prepared to participate and a replacement school was selected.

After consent, an interview was conducted with the child (where appropriate), parents or other care givers, teachers, and other witnesses to the incident. To facilitate recall, the interview was conducted as soon as practicable and, whenever possible, at the site of the incident. When the latter was not possible, photographs and diagrams of the site were used to assist the child in describing the incident, with measurements being made on site. Identical information was sought from cases and controls. The structured interview covered the gender, age, height, and weight of the child; date and time of the incident; place of occurrence and type of equipment; height from which the child fell; type of surface; particle size, depth, and retention of loose fill materials; and body part to hit first. Because no economically feasible test equipment was available, the critical drop heights for surfaces were not measured directly. The interviews were conducted by one of three persons in Dunedin, and one in Christchurch.

For cases, diagnostic information was obtained from the emergency department records. For controls, details of any nonmedically treated injuries were obtained during the interview. Body site, nature, and severity of injury were coded according to the abbreviated injury scale (AIS). ${ }^{23}$

\section{DEFINITIONS}

The definitions used were:

(1) A 'fall' was defined as any action, including jumping, in which a child descended or dropped freely from an item of playground equipment to the ground surface below.

(2) The 'height of fall' was defined as the vertical distance the child fell and was measured from the point on the equipment at which the child was sitting, standing, kneeling, swinging, or balancing, to the ground surface.

(3) Surfaces were classified as impact absorbing' or 'non-impact absorbing' in accordance with NZS 5828 (see Appendix). This classification was made irrespective of critical drop height, or, in the case of loose fill materials, particle size, depth, and retention characteristics.

(4) The 'safe fall height' for a given surface material was taken from NZS 5828, with the exception of bark chips (table 1). For bark 
Table 1 Safe fall heights for selected playground surface materials

\begin{tabular}{ll}
\hline Material & $\begin{array}{l}\text { Safe fall height } \\
(\mathrm{mm})\end{array}$ \\
\hline $\begin{array}{l}\text { Impact absorbing } \\
\text { Loose fill }\end{array}$ & \\
Bark chips (minimum depth $200 \mathrm{~mm})$ & $\leqslant 2500$ \\
$\begin{array}{l}\text { Pea gravel (minimum depth } 200 \mathrm{~mm}) \\
\text { Sand (minimum depth } 300 \mathrm{~mm})\end{array}$ & $\leqslant 2000$ \\
$\begin{array}{l}\text { Synthetic } \\
\text { Rubber matting }\end{array}$ & $\leqslant 2000$ \\
Rubber tiles & $\leqslant 1600$ \\
Non-impact absorbing & $\leqslant 1350$ \\
Concrete & \\
Asphalt & $\leqslant 250$ \\
Grass & $\leqslant 50$ \\
Bare earth & Not applicable \\
\hline
\end{tabular}

* Grass and bare earth are not considered suitable under fixed or high use equipment (NZS 5828: part 1: s105.9).

chips, the safe fall height was set at $2500 \mathrm{~mm}$, the maximum permissable fall height, to reflect the results of more recent tests conducted in New Zealand.

\section{STATISTICAL ANALYSIS}

All analyses were conducted using the SAS system for personal computers. ${ }^{24}$ Goodness of fit in the logistic regression model was assessed using the test statistic proposed by Hosmer and Lemeshow. ${ }^{25}$ On the basis of preliminary bivariate analyses, all of the logistic regression models were adjusted for place of occurrence (early childhood education centre $v$ school), type of equipment, age (0-9 years, 10-14 years), and gender. With one exception, the falls among 0-4 year olds occurred in early childhood centres and the falls among 5-9 year olds occurred in schools. Controlling for place of occurrence is very similar, therefore, to controlling for differences in the risk of injury between $0-4$ and 5-9 year olds. All were adjusted also for child height and weight, because these factors are considered to affect the risk of injury in free falls. ${ }^{26}$ Additive interaction between variables was assessed using the indices proposed by Rothman, ${ }^{27}$ and confidence intervals (CIs) for these indices were calculated. ${ }^{28}$ Attributable proportions were estimated using the method described by Rothman. $^{27}$

\section{Results}

During the periods described above, 126 children meeting the initial case criteria (67 in Dunedin and 59 in Christchurch) and 205 children meeting the initial control criteria were interviewed. These represented $78 \%$ of eligible cases in Christchurch, $76 \%$ of eligible cases in Dunedin, and $96 \%$ of eligible controls. After the exclusion of 16 cases and 15 controls, a total of 110 cases (57 from Dunedin and 53 from Christchurch), and 190 controls were entered into the analysis.

There were proportionally more males and older children (aged 10-14 years) among the cases, and while not differing by mean height they were heavier than controls (table 2). For the cases, the most common site of injury was the upper extremity $(76 \%)$, the most common
Table 2 Personal and injury characteristics of cases and controls; values are number $(\%)$ unless stated otherwise

\begin{tabular}{|c|c|c|c|}
\hline & $\begin{array}{l}\text { Cases } \\
(n=110)\end{array}$ & $\begin{array}{l}\text { Controls } \\
(n=190)\end{array}$ & Test statistic \\
\hline $\begin{array}{c}\text { Gender } \\
\text { Female } \\
\text { Male }\end{array}$ & $\begin{array}{l}51(46) \\
59(54)\end{array}$ & $\begin{array}{r}114(60) \\
76(40)\end{array}$ & $\begin{array}{l}\chi^{2}=5 \cdot 234, \mathrm{df}=1 \\
\mathrm{p}=0.022\end{array}$ \\
\hline $\begin{array}{l}\text { Age (years) } \\
0-4 \\
5-9 \\
10-14\end{array}$ & $\begin{array}{l}10(9) \\
74(67) \\
26(24)\end{array}$ & $\begin{array}{r}28(15) \\
146(77) \\
16(8)\end{array}$ & $\begin{array}{l}\chi^{2}=14 \cdot 143, \mathrm{df}=2 \\
\mathrm{p}=0.001\end{array}$ \\
\hline $\begin{array}{l}\text { Mean height }(\mathrm{mm}) \\
\text { Mean weight }(\mathrm{kg})\end{array}$ & $\begin{array}{r}1265 \\
27\end{array}$ & $\begin{array}{r}1240 \\
25\end{array}$ & $\begin{array}{l}t=1.47, \mathrm{p}=0.143 \\
t=2.48, \mathrm{p}=0.014\end{array}$ \\
\hline $\begin{array}{l}\text { Site of injury } \\
\text { No injury } \\
\text { Head } \\
\text { Face } \\
\text { Abdomen } \\
\text { Upper extremity } \\
\text { Lower extremity } \\
\text { Other }\end{array}$ & $\begin{array}{l}0 \\
8(7) \\
2(2) \\
5(5) \\
84(76) \\
11(10) \\
0\end{array}$ & $\begin{array}{l}54(28) \\
27(14) \\
28(14) \\
22(12) \\
22(12) \\
34(18) \\
3(2)\end{array}$ & \\
\hline $\begin{array}{l}\text { Nature of injury } \\
\text { No injury } \\
\text { Abrasion } \\
\text { Contusion } \\
\text { Sprain } \\
\text { Fracture } \\
\text { Intracranial } \\
\text { Other }\end{array}$ & $\begin{array}{l}0 \\
0 \\
9(8) \\
6(6) \\
65(59) \\
8(7) \\
22(20)\end{array}$ & $\begin{array}{l}54(28) \\
32(17) \\
68(36) \\
13(7) \\
0 \\
1(1) \\
22(11)\end{array}$ & \\
\hline $\begin{array}{l}\text { Severity of injury } \\
\text { No injury } \\
\text { AIS1 minor } \\
\text { AIS2 moderate } \\
\text { AIS3 serious } \\
\text { AIS unknown }\end{array}$ & $\begin{array}{l}0 \\
35(32) \\
54(49) \\
17(15) \\
4(4)\end{array}$ & $\begin{array}{c}54(28) \\
131(69) \\
1(1) \\
0 \\
4(2)\end{array}$ & \\
\hline
\end{tabular}

diagnosis a fracture $(59 \%)$, and over half were assigned an $\mathrm{AIS}^{23}$ severity score of $\geqslant 2$ (moderate). In contrast, $54(28 \%)$ of the controls sustained no injury, while for those injured, the most common site was the lower extremity $(18 \%)$, the most common injury a contusion $(35 \%)$, and all but one was assigned a severity score of 1 (minor). The groups did not differ significantly by place of occurrence or equipment type (table 3).

For cases, the upper extremity was the most common body part to hit the ground first $(71 \%)$, followed by the lower extremity $(14 \%)$. For controls, the lower extremity was the most common body part to hit first ( $41 \%)$, followed by the upper extremity (19\%). For cases, $63 \%$ of falls from 1 metre and below hit with the upper extremity first, compared with $73 \%$ of falls from above 1 metre. For controls, $14 \%$ of falls from 1 metre and below, the upper extremity hit first, compared with $22 \%$ of falls from above 1 metre. To avoid collinearity problems, body part to hit first was not included in the logistic regression models.

An initial logistic regression model including place of occurrence, age, gender, child height, child weight, equipment type, impact surface, and fall height was fit. The model provided an adequate fit to the data (Hosmer-Lemeshow $C=4 \cdot 72, d f=8, p=0 \cdot 7866$ ).

\section{NON-COMPLIANCE WITH THE STANDARD}

To test hypothesis 1(a) the height of interest was that from which the child fell (that is height of fall) and whether this exceeded 2.5 metres. Although most children fell from heights of less than 2.5 metres, $5 \%$ of the cases and $2 \%$ of the controls fell from heights exceeding this, imp- 
Table 3 Characteristics of falls from playground equipment; values are number ( $\%$ ) unless stated otherwise

\begin{tabular}{|c|c|c|c|}
\hline & $\begin{array}{l}\text { Cases } \\
(n=110)\end{array}$ & $\begin{array}{l}\text { Controls } \\
(n=190)\end{array}$ & Test statistic \\
\hline $\begin{array}{l}\text { Place of occurrence } \\
\text { Early childhood centre } \\
\text { School }\end{array}$ & $\begin{array}{c}9(8) \\
101(92)\end{array}$ & $\begin{array}{r}28(15) \\
162(85)\end{array}$ & $\begin{array}{l}\chi^{2}=2.769, \text { df }=1 \\
p=0.096\end{array}$ \\
\hline $\begin{array}{l}\text { Equipment child fell from } \\
\text { Swinging } \\
\text { Sliding } \\
\text { Agility/climbing } \\
\text { Other }\end{array}$ & $\begin{array}{c}5(5) \\
7(6) \\
96(87) \\
2(2)\end{array}$ & $\begin{array}{c}9(5) \\
10(5) \\
169(89) \\
2(1)\end{array}$ & $\begin{array}{l}\chi^{2}=0.483, \mathrm{df}=3 \\
\mathrm{p}=0.923\end{array}$ \\
\hline $\begin{array}{l}\text { Height of fall } \\
\text { Range (mm) } \\
\text { Maximum } \\
\text { Minimum } \\
\text { Mean }\end{array}$ & $\begin{array}{r}2860 \\
220 \\
1610\end{array}$ & $\begin{array}{r}2965 \\
100 \\
1291\end{array}$ & \\
\hline $\begin{array}{l}\text { In compliance with standar } \\
\text { Yes } \\
\text { No }\end{array}$ & $\begin{array}{l}\text { d (that is } \leqslant \\
104(95) \text {, } \\
6(5)\end{array}$ & $\begin{array}{l}0 \mathrm{~mm}) \\
187(98) \\
3(2)\end{array}$ & \\
\hline $\begin{array}{l}\text { Type of surface } \\
\text { Impact absorbing } \\
\text { Loose fill } \\
\text { Synthetic }\end{array}$ & $\begin{array}{c}84(76) \\
6(6)\end{array}$ & $\begin{array}{c}155(82) \\
14(7)\end{array}$ & \\
\hline $\begin{array}{l}\text { Non-impact absorbing } \\
\text { Concrete/asphalt/paving } \\
\text { Bare earth/grass } \\
\text { Other }\end{array}$ & $\begin{array}{l}1(1) \\
18(16) \\
1(1)\end{array}$ & $\begin{array}{r}4(2) \\
12(6) \\
5(3)\end{array}$ & \\
\hline $\begin{array}{l}\text { In compliance with standar } \\
\text { Yes } \\
\text { No }\end{array}$ & $\begin{array}{l}\text { (that is im } \\
90(82) \\
20(18)\end{array}$ & $\begin{array}{l}\text { t absorbing) } \\
169(89) \\
21(11)\end{array}$ & \\
\hline
\end{tabular}

Table 4 OR (95\% CI) for injury requiring medical attention associated with type of surface and height of fall

\begin{tabular}{|c|c|c|}
\hline & Unadjusted & Adjusted \\
\hline $\begin{array}{l}\text { Type of surface } \\
\text { Non-impact absorbing } v \text { impact absorbing } \\
\text { Non-impact absorbing } v \text { loose fill } \\
\text { Non-impact absorbing } v \text { synthetic } \\
\text { Loose fill } v \text { synthetic }\end{array}$ & $\begin{array}{l}1.79(0.92 \text { to } 3.47) \\
1.76(0.90 \text { to } 3.43) \\
2.22(0.71 \text { to } 6.92) \\
1.27(0.47 \text { to } 3.41)\end{array}$ & $\begin{array}{l}2.28(1.04 \text { to } 4.96) \\
2.27(1.04 \text { to } 4.97) \\
2.31(0.56 \text { to } 9.53) \\
1.02(0.29 \text { to } 3.56)\end{array}$ \\
\hline $\begin{array}{l}\text { Height of fall } \dagger \\
\text { Broad categories (metres) } \\
1.0 \text { and below } \\
1.0-1.5 \\
1.5-2.0 \\
\text { Over } 2.0\end{array}$ & $\begin{array}{l}1.00 \text { (referent) } \\
1.80(0.90 \text { to } 3.59) \\
2.85(1.50 \text { to } 5.45) \\
8.60(3.50 \text { to } 21.11)\end{array}$ & $\begin{array}{l}1.00 \text { (referent) } \\
1.72(0.78 \text { to } 3.83) \\
4.14(1.96 \text { to } 8.77) \\
10.62(3.86 \text { to } 29.19)\end{array}$ \\
\hline $\begin{array}{l}\text { Narrow categories (metres) } \\
0.75 \text { and below } \\
0.75-1.00 \\
1.00-1.25 \\
1.25-1.50 \\
1.50-1.75 \\
1.75-2.00 \\
2.00-2.25 \\
\text { Over } 2.25\end{array}$ & $\begin{array}{l}1.00 \text { (referent) } \\
0.64(0.23 \text { to } 1.78) \\
1.44(0.55 \text { to } 3.80) \\
1.31(0.45 \text { to } 3.81) \\
1.84(0.67 \text { to } 5.06) \\
2.45(0.99 \text { to } 6.09) \\
5.30(1.52 \text { to } 18.50) \\
8.67(2.22 \text { to } 33.84)\end{array}$ & $\begin{array}{l}1.00 \text { (referent) } \\
0.97(0.32 \text { to } 2.91) \\
1.96(0.66 \text { to } 5.85) \\
1.34(0.40 \text { to } 4.50) \\
3.85(1.22 \text { to } 12.13) \\
4.23(1.47 \text { to } 12.20) \\
8.53(2.08 \text { to } 35.09) \\
12.94(2.90 \text { to } 57.71)\end{array}$ \\
\hline $\begin{array}{l}\text { Interaction } \\
\text { Height of fall (metre) }\end{array}$ & $\begin{array}{l}\text { Impact absorbing } \\
\text { surface }\end{array}$ & $\begin{array}{l}\text { Non-impact absorbing } \\
\text { surface }\end{array}$ \\
\hline $\begin{array}{l}\text { Unadjusted } \\
1.5 \text { and below } \\
\text { Over } 1.5\end{array}$ & $\begin{array}{l}1.00 \text { (referent) } \\
2.84(1.68 \text { to } 4.82)\end{array}$ & $\begin{array}{l}1.92(0.83 \text { to } 4.47) \\
9.44(2.42 \text { to } 36.87)\end{array}$ \\
\hline $\begin{array}{l}\text { Adjusted OR } \ddagger \\
1.5 \text { and below } \\
\text { Over } 1.5\end{array}$ & $\begin{array}{l}1.00 \text { (referent) } \\
3.80(2.01 \text { to } 7 \cdot 17)\end{array}$ & $\begin{array}{c}1.83(0.72 \text { to } 4.63) \\
14.89(3.33 \text { to } 66.54)\end{array}$ \\
\hline
\end{tabular}

*Adjusted for place of occurrence, age, gender, child weight, child height, type of equipment, and height of fall (broad categories). †Adjusted for place of occurrence, age, gender, child weight, child height, type of equipment, and impact surface (impact absorbing $v$ non-impact absorbing). $\ddagger$ Adjusted for age, gender, place of occurrence, child weight, child height, and type of equipment. with falls from less than 2.5 metres. This suggested an increased risk of injury from falling from equipment that exceeded the maximum permissible fall height.

For $18 \%$ of cases and $11 \%$ of controls, the surface hit failed to comply with the surfacing requirement of NZS 5828 (table 3). Because no controls hit surfaces that fully complied with all of the loose fill requirements, only surface type was used in this analysis. To test hypothesis 1(b), four logistic regression models including height of fall were fit to the data (table 4). The first model indicated that there was an increased risk of injury associated with falling onto non-impact absorbing surfaces compared with impact absorbing surfaces. The results of the second and third models showed that this was true for both loose fill and synthetic surfaces. The final model suggested there was no difference in the risk of injury associated with falling onto synthetic surfaces compared with loose fill surfaces.

Twenty five per cent of cases and $14 \%$ of controls fell in circumstances that failed to meet the safe fall height requirement. Because there was a general lack of conformity with the minimum depth specified for loose fill materials, non-compliance was defined as the absence of an impact absorbing surface or a height of fall exceeding the minimum height specified for the material involved (table 1). To test hypothesis 1 (c), a single regression model was fit to the data. After adjusting for the confounding factors an OR $(95 \% \mathrm{CI})$ of $2 \cdot 13$ $(1.12$ to 4.03$)$ (unadjusted $\mathrm{OR}=2.06(1.14$ to 3.72)) was obtained, indicating that there was an increased risk of injury associated with falling in circumstances that failed to comply with the safe fall height requirement.

\section{HEIGHT OF FALL}

To test hypothesis 2 we wished to determine at what height, or range of heights, the greatest increase in risk occurred (table 4). We did this by fitting a series of logistic regression models to the data. For the first of these models height of fall was grouped into 'broad' categories, at 0.5 metre intervals, with the reference category being falls of 1 metre or less. The results indicated that the odds of injury increased with increases in the height of the fall and that a marked increase occurred when the category 1.5 to 2.0 metres was reached. This trend was evident for the unadjusted ORs and was increased after adjustment for confounders. An increasing trend was evident, also, when height of fall was also grouped into 'narrow' categories, at 0.25 metre intervals. Finally, the height of fall was grouped into one of two categories, those over 1.5 metres and those 1.5 metres and below (reference category). An adjusted OR (95\% CI) of $4.14(2 \cdot 26$ to $7 \cdot 61)$ (unadjusted $\mathrm{OR}=2.78(1.71$ to 4.51$)$ ) was obtained, which indicated that a marked increase in the risk of injury was associated with falls from heights in excess of 1.5 metres.

A term representing the interaction between height of fall (in two levels) and impact surface was included to determine if increasing risk estimated an odds ratio (OR) of 3.00 ( $95 \%$ CI 0.69 to 13.07$)$ (unadjusted $O R=3.60(0.88$ to 14.68)) for falls from over 2.5 metres compared

lying that the equipment failed to comply with the maximum fall height requirement (table higher than that for controls. A logistic regression model including the confounding factors noted in the methods plus impact surface (impact absorbing $v$ non-impact absorbing), 
with increasing height of fall was similar for both impact absorbing and non-impact absorbing surfaces. The interaction term was not significant. For both the unadjusted and adjusted estimates, however, the 'relative excess risk' (estimated as the OR -1) for exposure to both factors was greater than the sum of the relative excess risks for exposure to the factors individually (that is $(1.83-1)+$ $(3.80-1)=2.63<(14.89-1)$ ) (table 4$)$, suggesting an additive interaction effect. Calculation of the synergy index (S) and the relative excess risk due to interaction (RERI), ${ }^{27}$ provided further evidence of an additive interaction for both the unadjusted model ( $\mathrm{S}=3.05$ (95\% CI 0.61 to 15.30$)$; RERI $=5.68$ (95\% CI -6.92 to $18 \cdot 26)$ ) and the adjusted model ( $\mathrm{S}=3.83 \quad(95 \% \quad \mathrm{CI} \quad 0.76$ to $19 \cdot 37)$; RERI $=10 \cdot 26(95 \% \mathrm{CI}-11 \cdot 37$ to $31 \cdot 90))$.

ESTIMATES OF ATTRIBUTABLE PROPORTION To estimate the potential reduction in attendances at emergency departments that could be achieved if all equipment was to comply with the height and surfacing requirements of NZS 5828 , we calculated attributable proportions for each requirement. ${ }^{27}$ Annually, in New Zealand, about 4300 children attend emergency departments for injuries from falls from playground equipment. ${ }^{1}$ We estimate that $85 \%$ (3650) of these children are injured on hitting the ground surface, and that of these incidents, nearly $60 \%$ (2200) occur in schools or early childhood education centres.

If all items of playground equipment at these sites complied with the requirement that no fall height is to exceed 2.5 metres, there would be a $3.6 \%$ reduction in the number attending emergency departments ( $\mathbf{P}$ (proportion of cases exposed) $=0.0545$ ), that is a reduction of 80 such attendances. Similarly, if all equipment was installed over well maintained impact absorbing surfaces, there would be a $10 \%$ reduction in attendances $(P=0 \cdot 1818)$, that is 220 fewer attendances. If all equipment met the safe fall requirement, which requires that both height and surface are in conformity, there would be a $13.5 \%$ reduction $(P=0.2545)$, that is 300 fewer attendances. If the maximum permissible fall height were lowered to 1.5 metres and all equipment complied, the estimated reduction would be $45 \%$ $(P=0.5905)$, that is 990 fewer attendances. Finally, 5.6\% $(P=0.056)$ of cases are attributable to the interaction between height of fall and impact surface, that is 125 attendances.

\section{Discussion}

\section{LIMITATIONS}

The selection and recruitment of cases and controls for this study presented a number of challenges. Cases were selected from children presenting at hospital emergency departments because this enabled both accessibility and a minimum of delay between injury and interview. Checks made with private emergency services and general practitioners revealed that few children injured on playground equipment presented at these services. It is unlikely, therefore, that limiting our case selection introduced any significant biases.

The second, and more demanding challenge, was to identify a control group who had fallen from playground equipment but had not been injured, and who would be accessible for interview. We chose children from early childhood education centres and schools, as these were the only setting where personnel maintained records of incidents. As the cases could have been injured in any setting, including public playgrounds and private homes, we limited them to those occurring in the same settings as controls, effectively reducing the generalizability of the findings.

Controls were limited to only those children who came to the attention of staff. Because not all children who fall from playground equipment seek attention, or in some other way come to the attention of staff, it is possible that this group may have differed from the population of children who fall from equipment. Because we assumed that those who did not seek attention were those whose fall was less serious, this non-ascertainment would yield conservative estimates of risk.

Because of sample size and logistics, it was necessary to conduct the study in two cities, with the cases being ascertained in Dunedin and Christchurch and the controls being ascertained only in Christchurch. This raises the potential bias that the characteristics of playgrounds and playground equipment in the two cities are different. To address this issue, we repeated the logistic regression analyses with the Dunedin cases excluded; the results were very similar to those reported for the full data set.

Controls were ascertained only from the larger early childhood education centres and schools. Because these may have been wealthier and better able to provide playgrounds that complied with the standard, this may have led to overestimates of the effectiveness of the height and surfacing requirements.

A potential source of bias was the definition of height of fall in a situation where a child is suspended beneath equipment. Using the distance from the lowest part of the child's body to the impact surface is unsatisfactory, given that many injuries are to the upper limbs. Where a child is suspended by the hands, for example, the distance traversed by the upper limb during descent is much greater than the distance between the lowest part of the child's body and the ground. Height of fall was, therefore, measured from the point where the child last had contact with the equipment, as it was considered that this would more accurately reflect the distance traversed by the majority of the injured body sites. This was consistent with the measurement for children standing, sitting, kneeling, or balancing.

We were unable to examine the effects of non-compliance with the requirements relating to particle size, depth, and retention of loose fill materials. This was due to a general lack of compliance with these requirements and con- 
forms to previously reported results. ${ }^{12}$ As it applied equally to cases and controls, it is doubtful that this introduced any significant biases. When we came to examine the safe fall height requirement, the lack of conformity with the minimum depth requirement obliged us to apply a less stringent test of compliance. Had we been able to measure the critical drop height for each surface directly, then a more precise test of compliance would have been possible. As with all of the measurements relating to surfacing, however, any apparent increase in precision must be weighed against the potential for bias due to differences in factors such as compaction and moisture content, as well as interventions by maintenance staff (for example raking), between the time of the fall and the time of testing. Finally, when we came to examine height of fall, we were unable to adjust for the depth of loose fill materials because there was insufficient variation in the data, with most surfaces being less than half of the depth required. As a result of these limitations, our estimates of risk and attributable proportions may be conservative.

\section{FINDINGS}

Our results show that children who fall from playground equipment that does not comply with the height and surfacing requirements of the New Zealand playground standard (NZS 5828) are at increased risk of injury. Firstly, non-compliance with the requirement that no child should be able to fall from a height exceeding 2.5 metres increases the odds of injury by 3.0 times. Secondly, the odds of being injured in a fall onto a non-impact absorbing surface, such as asphalt or concrete, is $2 \cdot 28$ times that of falling onto an impact absorbing surface. Thirdly, non-compliance with the safe fall height requirement (that no child should fall from a height which exceeds the critical drop height for the underlying surface), increases the odds of being injured by at least $2 \cdot 13$ times.

The greatest increase in risk occurred at heights in excess of 1.5 metres. When the interaction between height of fall and impact surface was examined, it was found that these factors tended to interact such that the odds of sustaining injury in falls from heights greater than 1.5 metres onto non-impact absorbing surfaces was very much greater than was the case when either one of these factors was involved. Not only does this finding have biological plausibility, but it also confirms the importance of providing both an impact absorbing surface and restricting the height from which children may fall.

Compliance with the existing maximum fall height requirement would not significantly reduce the number of children attending emergency departments. On the other hand, compliance with the surfacing requirement could be expected to prevent 220 cases. This figure would increase to 300 fewer cases if the safe fall height requirement were complied with. The greatest reduction would come about, however, by lowering the maximum fall height from 2.5 to 1.5 metres, that is a reduction of 990 cases. These estimates consider only injury occurring in early childhood education centres and schools. If all public playgrounds and domestic equipment were to comply with these requirements, then the reduction in attendances could be very much greater.

The findings indicate that both the maximum permissable fall height of 2.5 metres and the present safe fall height requirement should be reviewed. If the maximum permissable fall height were to be lowered from 2.5 metres to 1.5 metres, this could pose a significant problem with regard to existing equipment. For example, $59 \%$ of the climbing frames in Dunedin schools exceeded 1.5 metres when surveyed in $1989 .{ }^{12}$ While it might be difficult, therefore, to apply such a restriction retrospectively, such a requirement could be introduced for all future equipment. Informal discussion with both designers and manufacturers indicated this to be a reasonable proposal. It should be possible to design equipment so that no fall height exceeds 1.5 metres, while still providing children with the challenge and excitement they seek and that is important for their development. ${ }^{29}$

The critical drop height for a given surface material is presently set at the threshold for serious head injury based on experimental data using cadavers and animals. While we were unable to examine this directly, our findings suggest that this criterion may not be appropriate for the prevention of injury to any body site and, in particular, fractures to the upper limb (see Ball and $\mathrm{King}^{22}$ ). There are a number of ways in which this issue might be addressed. One would be to re-examine the critical drop height criterion and set a level appropriate to the more commonly occurring injuries associated with falls from playground equipment. A second would be to adopt a lower maximum permissible fall height of 1.5 metres. A third would be to consider others factors associated with surface impacts, but these would need to be amenable to change.

A significant proportion of school playground equipment does not comply with the surfacing requirement, and even where an impact absorbing surface has been installed, it is unlikely to comply fully with all of the relevant requirements. ${ }^{12}$ Because we were unable to assess the effectiveness of compliance with these requirements, further research is required. In particular, it would be of considerable interest to know if the present depth requirements for loose fill surface materials are adequate.

\section{Conclusions}

We observed increased risk of injury in falls from heights above those recommended in the New Zealand playground standard, and in falls onto surfaces that did not comply with the requirements of the standard. We conclude, therefore, that the height and surfacing requirements of the standard are effective in preventing injury in falls from playground equipment. We recommend that pending fur- 
ther research on critical drop heights and other factors associated with surface impacts, consideration be given to lowering the maximum permissible fall height specified in the New Zealand standard (NSZ 5828) from 2.5 metres to 1.5 metres. This would appear to provide the greatest opportunity for reducing the incidence of injury occurring in falls from playground equipment.

\section{Appendix: Height and requirements of NZS 5828}

(1) MAXIMUM FALL HEIGHT

No piece of equipment shall be of a height in excess of $6 \mathrm{~m}$ and no fall height therein in excess of $2.5 \mathrm{~m}$. (NZS 5828: part 3: s2.2.1)

\section{(2) SURFACING}

It is strongly recommended that impact absorbing surfaces be provided in at least the operating area . . . around equipment, particularly those items from which falls are possible. The major consideration in determining the surfacing must be the height of the apparatus that is going to be installed on that surface and the probability of a drop onto the head from that equipment. (NZS 5828: part 1: s105.9.1)

Impact absorbing surfaces include loose fill (for example bark chips, pea gravel, sand) and synthetic materials (for example rubber matting, rubber tiles, wet pour materials) and non-impact absorbing materials include concrete, asphalt, bare earth, and grass. Additional requirements relating to the particle size, depth, and retention of loose fill materials are specified (NZS 5828: part I: s105.9.2.1). A procedure for testing the impact absorbency of surface materials, based on ASTM F $355-78,{ }^{30}$ is specified, with which the 'critical drop height' for any given surface can be determined. Critical drop height is defined as 'a height in metres at which head concussion may occur, resulting from a peak deceleration of $250 \mathrm{~g}$ (or a severity index of 1000) or higher' (NZS 5828: part 1: s103.1).

\section{(3) SAFE FALL HEIGHT}

The range of heights above a specific surfacing material from which a child may fall with a minimum possibility of head concussion. (NZS 5828: part 1: s103.1)

This requirement relates to both height and surfacing, and to assist in the selection of a suitable surface material, given the maximum fall height of an item of equipment, a table of 'safe fall heights' for a number of common materials is provided (NZS 5828: part 1: table A1 of Appendix A).

The authors wish to thank Dr Gordon Smith, Dr Jean Langlois, and Dr Anna Waller for their assistance in formulating the hypotheses and in designing this study; Ms Sheila Williams for statistical assistance; Dr Penelope Keyl and Dr Ron Somers for their comments on earlier versions of this paper; Dr Peter
Bamford, Mr Alan Chirnside, Mrs Shirley Searle, and the reception staff of the Dunedin and Christchurch Hospital

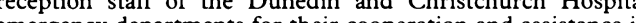
emergency departments for their cooperation and assistance in ascertaining cases, and the principals, secretaries, and staff of
early childhood education centres and schools for their cooperaearly childhood education centres and schools for their cooperation and assistance in ascertaining controls. We wish to ack-
nowledge also, the support and assistance of local authorities and nowledge also, the support and assistance of local authorities and educational authorities in Dunedin and Christchurch. Finally,
we wish to express our gratitude to the children and their parents we wish to express our gratitude to the child
for agreeing to take part in this study.

for agreeing to take part in this study.
This research was funded by means of a grant awarded to Drs JD Langley and DJ Chalmers by the Health Research Council of New Zealand. The Injury Prevention Research Unit is funded jointly by the Accident Rehabilitation and Compensation Insurance Corporation (ACC) and the Health Research Council of New Zealand.

1 Chalmers DJ. Falls from playground equipment: an overview. Proceedings of childhood injury prevention forum. Accident Prevention Foundation, 1992: 1-9.

2 Chalmers DJ, Langley JD. Childhood falls from playground equipment resulting in admission to hospital: descriptive epidemiology. In: Sime JD, ed. Safety in the built environment. London: Spon, 1988: 226-37.

3 Chalmers DJ, Langley JD. Epidemiology of playground equipment injuries resulting in hospitalization. $\mathcal{f}$ Paediat Child Health 1990; 26: 329-34.

4 King K, Ball D. A holistic approach to accident and injur prevention in children's playgrounds. London: LSS, 1989

5 Nixon J, Pearn J. Death during play: a study of playground and recreation deaths in children. $B M F$ 1981; 283: 410 .

6 Pitt R, cited in King K, Ball D. A holistic approach to accident and injury prevention in children's playgrounds. London: and injury prev.

7 Standards Association of New Zealand. Standard specification for playgrounds and playground equipment (NZS 5828: 1986). Wellington: Standards Association of New Zealand: 1986.

8 Standards Association of Australia. Australian Standard for playground equipment for parks, schools, and domestic use (AS 1924: 1981). Sydney: Standards Association of Australia, 1981.

9 British Standards Institution. Play equipment intended for permanent installation outdoors (BS 5696: 1986). London: British Standards Institution, 1986.

10 Canadian Standards Association. A guideline on children's playspaces and equipment (CAN/CSA-Z614-M90). Rex-
dale (Toronto): Canadian Standards Association, 1990.

11 ASTM. Standard consumer safety performance specification for playground equipment for public use (F1487-93) for playground equipment for public use (F1487-93).
Philadelphia, PA: American Society for Testing and Mhiladelphia, PA:

12 Evans MJ, Chalmers DJ. Compliance of Dunedin playground equipment with the New Zealand standard (NZS 5828). Dunedin: Injury Prevention Research Unit, 1992

13 Sacks JJ, Holt KW, Holmgren P, Colwell LS, Brown JM Playground hazards in Atlanta child care centers. $A m \mathcal{F}$ Public Health 1990; 80: 986-8.

14 Sosin DM, Keller P, Sacks JJ, Kresnow M, van Dyck PC. Surface-specific fall injury rates on Utah school playgrounds. Am ₹ Public Health 1993; 83: 733-5.

15 Mott A, Evans R, Rolfe K, Potter D, Kemp KW, Sibert JR. Patterns of injuries to children on public playgrounds. Arch Dis Child 1994; 71: 328-30.

16 Briss PA, Sacks JJ, Addiss DG, Kresnow M, O'Neil J. Injuries from falls on playgrounds: effects of day care center regulations and enforcement. Arch Pediatr Adoles Med 1995; 149: 906-11.

17 Ball D, King K. Risk in the playground: the case of synthetic surfacing. The Leisure Manager 1990; March: 21-3.

18 Suctliffe R. The real case for synthetic surfacing? The Leisure Manager 1990; April: 13-4.

19 King K, Ball D. Synthetic surfaces [letter to the editor]. The Leisure Manager 1990; May: 8.

20 Suctliffe R. Playground equipment and safety. The Groundsman 1990; 43: 19-21.

21 Jackson $\mathrm{H}$. The controversy over playground surfaces. Child Safety Review 1992; 6: 3.

22 Ball DJ, King KL. Playground injuries: a scientific appraisa of popular concerns. $\mathscr{F} R$ Soc Health 1991; 111: 134-7.

23 Association for the Advancement of Automotive Medicine. The abbreviated injury scale (1990 revision). Des Plaines: Association for the Advancement of Automotive Medicine, 1990.

24 SAS Institute. SAS language guide for personal computers, release 6.03 edition. Cary, NC: SAS Institute Inc, 1988.

25 Hosmer DW, Lemeshow S. Applied logistic regression. New York: John Wiley, 1989.

26 Warner KG, Demling RH. The pathophysiology of free-fal injury. Ann Emerg Med 1986; 15: 1088-93.

27 Rothman KJ. Modern epidemiology. Boston: Little, Brown 1986.

28 Hosmer DW, Lemeshow S. Confidence interval estimation of interaction. Epidemiology 1992; 3: 452-6.

29 Walsh P. Fixed equipment - a time for change. Australian Fournal of Early Childhood 1993; 18: $23-9$. 30 ASTM. Shock-absorbing properties of playing surface systems American Society for Testing and Materials, 1978. 